\title{
Total internal reflection
}

\section{The secret of the accidental immortals can now be made known.}

\section{Gwyneth Jones}

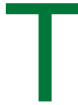
hey walk among us. They don't look young - you'd place them around 25 to 30: but the astonishing truth is that they are all (maybe half a million of them worldwide) over 600 years old. They have been talking to journalists, appearing on our screens: they've convinced us that this is no hoax. But why have they decided to leave Earth? That was the question I most wanted to ask, when I was offered the chance to interview our own, local, Thames Valley immortal. Why quit now, just when they don't need to hide anymore?

I met Tamsin in the garden of her house in a quiet Middlesex village: a light-skinned, dark-haired woman of average height, dressed in the dateless human uniform of blue jeans and white T-shirt. She reminded me that I'd agreed not to make a live broadcast. I let her check the output setting on my eye-socket ConjurMac, and we got down to business.

\section{"So," I said (never one to} avoid the obvious) "how does it feel to be 650?"

Tamsin laughed.

"How old are you?"

I am 97, and I said so.

"So why ask me? You'll find out soon enough."

I put it to her that if I survived - and no longevity treatment can guarantee survival - it was a long time to wait for an answer.

"When I first took rem," she said. "It was 2039 cE. It doesn't seem long ago at all. Trust me: the years will fly."

Their perception of time is different from ours: I stared, transfixed, at the woman who had lived through the squalor of the Population Pulse, survived five World Wars, kept her impossible secret since the fifteenth century after the Prophet (Praise And Blessings Of Allah Be Upon Him). If I hadn't known, I would never have guessed. She looked so normal.

In the mid-twenty-first century $\mathrm{CE}$, a new drug treatment for memory impairment went into clinical trials. It was meant to strengthen associative memory: in fact it gave patients bursts of recall so intense they were stopped in their tracks, lost in ecstatic re-experience of some childhood joy. Bootlegged rem quickly reached the streets, and

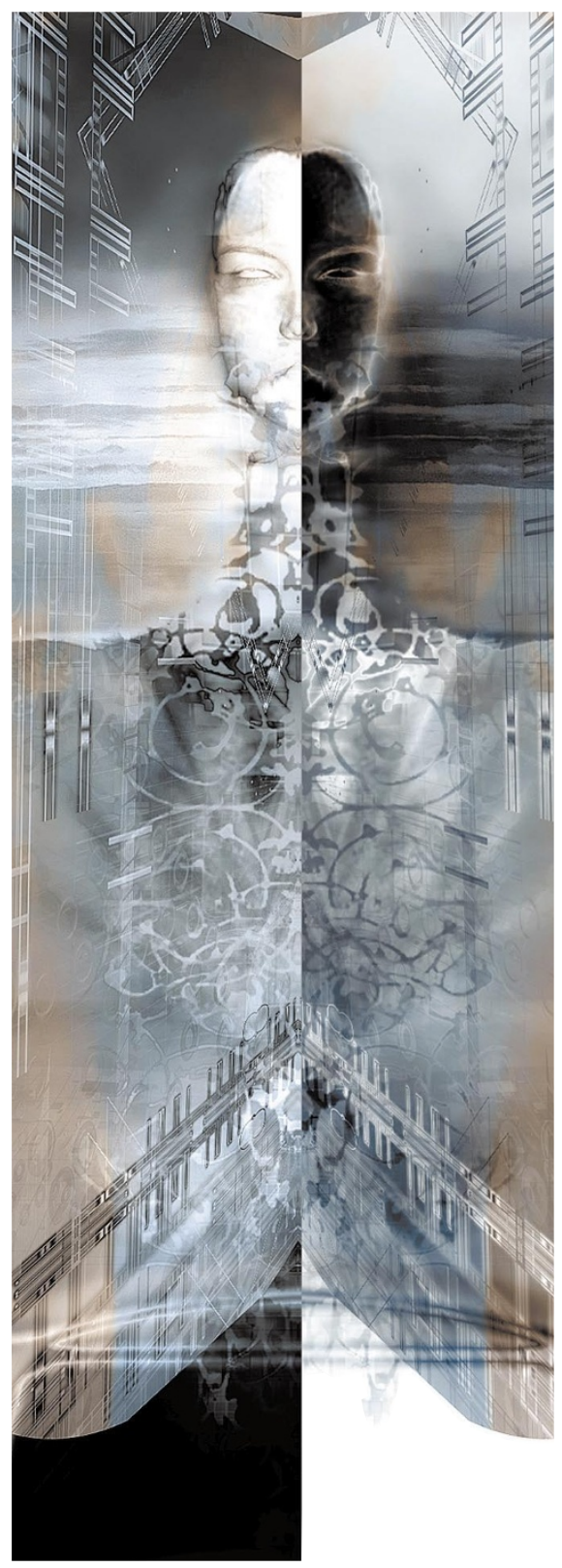

became fashionable. This was in the midst of the Third World War: reckless times. It didn't worry the users that the heart-stopping delight of a rem high was, in a few cases, literally heart stopping.

But the damage mounted. Prodromal schizophrenic symptoms, untreatable depression, vegetative coma - the clinical trials were dropped. All recreationals were legal by then, at least throughout Europe and most of the United States, but rem's reputation made it a poor business prospect. It vanished. The dosage given to the clinical subjects had been too low for the effect to emerge. When those who had taken it habit- ually realized what was happening to them, they kept quiet. So no one knew, except the immortals themselves.

They were wise to keep quiet. In those days and for a long time afterwards, the Population Pulse was a terrifying force. Longevity research had been abandoned: it was just too sensitive an issue. Rem was not intended to prolong life, only to ameliorate dementia and confusion.

But the Pulse is over, and other things have changed. It's not just the Lagrange colonies and the Moon, and the gruelling labour of love that is transforming Mars. Crucially, in a few months' time the first colony ships will leave Deep Space (our waystation on the brink of the heliopause), and travel, at speeds believed logically impossible when Tamsin was young, to a remote-surveyed, uninhabited, Earth-type planet. This year, 2108 (2688 by the CE count), we are free, at last. The treatments came too late for me. I may live to be 600 , but I will get old. For younger generations, there are no known limits.

But rem immortality is still different.

We chatted for two hours, sitting under an apple tree; the murmur of the Fleet (which runs by her garden) in the background. She talked about her son, so long dead; and her husband, killed in a climbing accident last century (immortality is not proof against blunt instruments, lynch mobs or equipment failure). She tried to explain how it feels to have your entire life available to you, so you can be there, again and again, in every moment. How you start with the good moments, then gather courage until you have taken possession of the whole, and your entire existence becomes coherent, like laser light in a perfect optical computer.

"But why are you leaving?" I insisted. "You have so much to teach us."

"It isn't a decision," she said. "It was a process of conversion."

She stood up, smiling, and walked away from me. The air around her shimmered. Next moment, I was alone.

Gwyneth Jones's recent books include Phoenix Café (Gollancz) and the non-fiction Deconstructing the Starships (University of Liverpool Press). 